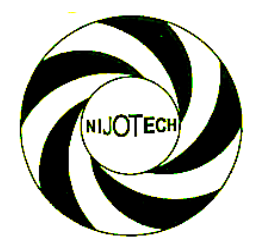

Nigerian Journal of Technology (NIJOTECH)

Vol. 35, No. 2, July 2016, pp. 598 - 607

Copyright@ Faculty of Engineering, University of Nigeria, Nsukka, Print ISSN: 0331-8443, Electronic ISSN: 2467-8821

www.nijotech.com

http://dx.doi.org/10.4314/njt.v35i3.19

\title{
SECURING DIGITIZED LIBRARY CIRCULATORY SYSTEM
}

\author{
0. M. Olaniyi ${ }^{1}$, B. K. Nuhu², S. A. Salau ${ }^{3}$, A. B. Musa ${ }^{4}$ and P. C. Oparaocha ${ }^{5}$

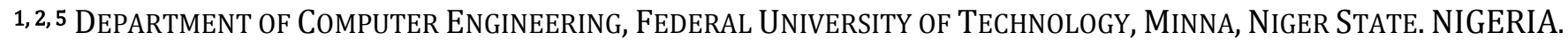

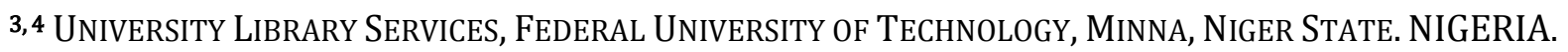 \\ E-mail addresses:1mikail.olaniyi@futminna.edu.ng,2nuhubk@futminna.edu.ng,3adetoro@futminna.edu.ng, \\ 4 adamu.musa@futminna.edu.ng, ${ }^{5}$ paschaloparaocha30@gmail.com
}

\begin{abstract}
Despite the potential benefits of Information and Communication Technology (ICT) in library automation, library operations in most developing countries are yet to migrate from traditional method of routine operations to automated systems. Current model of operation carries along with it challenges of insecurity of library books, errors in task execution, laborious routines with over dependency of human involvement in Library operations. In this paper, circulatory operations of the library were digitized and secured using a 125- KHz Radio Frequency Identification (RFID) technology with a blend of 192-bit Advanced Encryption Standard (AES) private key encryption technique. This ensured the confidentiality of patron's information and provided an auto-notification service. The results of testing and evaluation of the developed system showed that the surface area and position of the tag from RFID reader affects the response of the RFID system for improved library circulatory service delivery. The widespread application of the developed system on smart library circulation unit would improve the management of the library circulatory operations, give patrons better library circulatory experiences and enhance the productivity of library administrators.
\end{abstract}

Keywords: RFID, Confidentiality, Circulation, Library, Security

\section{INTRODUCTION}

Libraries have been yearning for better technologies even before the onset of computers. The introduction of typewriters into libraries was a revolutionary concept in late 1800 's. Later stage of modernization witnessed the introduction of unit record equipment. By the mid-60, computers were used for the production of Machine Readable Catalogue Records (MARC) by the Library of Congress (LOC) [1]. The advent of Information and Communication Technology (ICT) has brought about transformation in different aspects of human endeavor including education [2]. Many libraries today have been transformed from the manual to digital operations by using appropriate technology. New technology and communication tools are employed in rendering services to patrons to help curb the issues of theft and monotonous routine library services [3]. Library is the heart of every educational institute targeted at breathing knowledge and information into the mind of the students. Despite this irrefutable fact, libraries in developing countries are yet to meet up to this objective on account of its operations still being executed manually.

Radio Frequency Identification (RFID) technique belongs to the family of Automatic Identification (Auto-id) systems. These systems include Smart Cards, Barcode, Optical Recognition system, Biometrics and RFID. RFID system came into existence in 1969 and its application in the library operations for a blend of automation and security guarantees the sustenance of resources inside the library [2]. The idea of RFID is akin to the electronic barcode used to identify, track, and detect library holdings at the circulation desk and in the daily stock maintenance [4]. The library comprises of interconnected operational units working together to provide library services. These units are: Acquisition, Classification/Cataloguing, Circulation, Reference, Serial and Binding Unit [5], and more recently systems unit which provide electronic, digital and multimedia services.

In this paper, the circulation unit of a mini library was digitized and secured using hardware and software

*Corresponding author Tel: +234-706-217-5203 
control techniques. The circulation unit is responsible for patron's resource servicing and sundry activities such as registration of patrons, charging-in and charging-out of books and monitoring of library resources. The test bed adopted in this study for system requirement's engineering, testing and performance evaluation is the mini-library of School of Information and Communication Technology (SICT), Federal University of Minna, Niger State, Nigeria, West Africa.

The rest of the paper is organized into five sections: Section II provides the review of related work; Overview of basic elements of RFID is presented in section III; System Hardware and Software Design Considerations are presented in section IV; Results and Discussions were presented in section V, Section VI concludes and provides scope for future research endeavor

\section{RELATED WORKS}

Several related works have been reported in the application of RFID auto-identification systems for the provision of value added operation to library patrons, improve library administrator's productivity and protect library resources. In [2] and [6], an in-depth analysis of how RFID auto-id systems were applied to library automation in India was presented. These works gave an account of RFID growth steps from development to maturity. These works showed specific application of RFID in cataloguing and indexing library operations.

In [4], a clear description of the application of RFID technology in libraries, its components, benefits and the role of librarians was presented. The work showed the impact of RFID technology in library management enhancing the library check-in and check-out services and also provided anti-theft detection. The work lacked design consideration for user data confidentiality. In [7], personal privacy regarding the personal RFID tag was presented. The proposed method in [7] had probabilistic encryption scheme, common key encryption scheme and hash chain scheme proved to handle the privacy challenge encountered in active tag.

In developing countries ecosystem, authors in [5] illuminated on the application of Information and Communication Technology (ICT) in the organization of library reader's desk operation. This work integrated the biometric and the barcode system for patron's authentication. This enhanced the library operations for better efficiency. However, Barcode and Biometrics auto-id systems adopted in the work are not without limitations. Barcode stripes could be easily erased and the system design consideration for biometrics does not accommodate fingerprint shape, form and pattern over time.

An RFID Based Library Books security system was developed in [8]. This work focused mainly on the security of books in shelf, enabling the librarian to know when a book is taken and intact with the help of an alarm system integrated with the proposed system. The work lacked design consideration for database management to keep inventory of library resources. Authors in [9] developed a RFID based library management system and users access control. In their work, the library operations for book and patrons tracking were automated using a $125-\mathrm{KHz}$ passive RFID prototyping system. Their developed system lacked design consideration for patron's data privacy and was limited only to library cataloguing as well as user authentication application.

In this paper, we improved on these baselines related works by developing a secure system with a large and robust database and ensured privacy of patron's information by encrypting the detail of every registered user alongside sending notifications to patrons specifically for library circulation operations. This was achieved by enhancing the work in [8]through the addition of a robust and secure database management system; [9] through securing patrons information with 192-AES Cryptographic technique and narrowing library management to circulation operation and [7]by means of a secure contactless auto-identification system with a $125 \mathrm{KHz}$ Radio Frequency Identification (RFID) technology and a blend of 192-bit Advanced Encryption Standard (AES) private key encryption technique for smart, secure and improved library circulatory operations for both patrons and productive service delivery by library administrators.

\section{BASIC ELEMENTS OF RFID SYSTEMS}

The Radio Frequency identification (RFID) technology is one of numerous technologies grouped under the term Automatic Identification (Auto-ID). Auto-ID technologies are a new way of controlling information and material flow [10]. The application of RFID extends to all works of life ranging from health care, inventory, construction and parking management [6]. The operational principle of RFID is akin to that of electronic barcode and can be employed in monitoring, identifying and detecting library assets. RFID systems comprises of basically three components as shown in Figure 1 . These are transponders that carry unique information, readers 
or sensors to query the tags and the middleware to integrate the reader and tags [11].

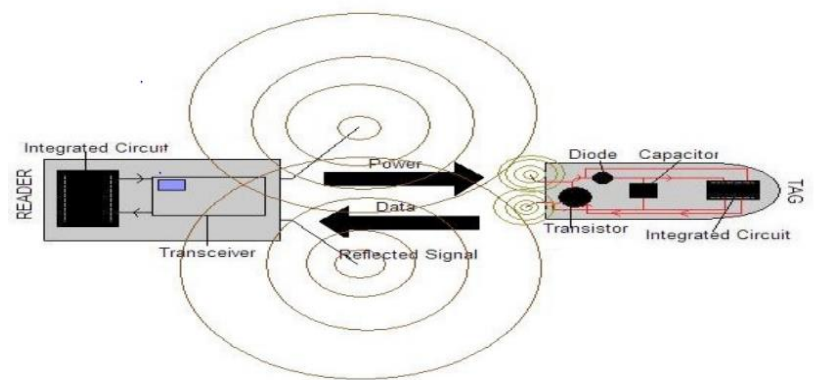

Figure 1: Components of RFID systems [11]

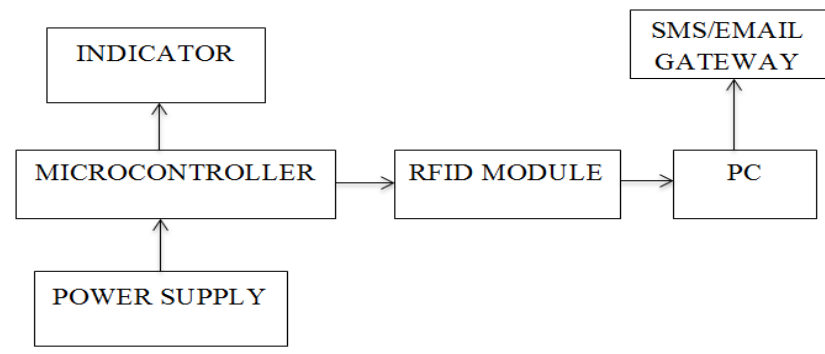

Figure 2: Overall Block Diagram of the Secure Digitized Library Circulatory System

\section{SYSTEM DESIGN}

This section describes the methodology used in the design of the Secure Automated Library Circulatory system. The methodology is described according to system overview, hardware and software design considerations.

\subsection{System Overview}

The system block diagram in Figure 2 shows the various units that made up the developed system. The block diagram comprised of the following units: The power supply unit, the SMS/Email gateway unit which permits sending out of notification to Library users, the PIC16F887 microcontroller which synchronizes the hardware to properly communicate with the software, the indicator designed around light emitting diodes to show when the system is ready for use or otherwise, the RFID module and the Personal Computer (PC) which hosts the application software design around library front end system and robust database management back end system.

\subsection{System Hardware Design Consideration 4.2.1 The power Supply Unit:}

The simplified power supply unit shown in Figure 3 is responsible for providing a stabilized power to the microcontroller unit of Figure 2. It comprises a supply from $12 \mathrm{~V}$ step down transformer which steps down the $220 \mathrm{~V}$ from the mains to $12 \mathrm{~V}$, a rectifier bridge to convert from Alternating Current (AC) to Direct
Current (DC), a capacitor to filter out any un-rectified AC and an LM7805 voltage regulator to stabilize the output voltage to $5 \mathrm{~V}$. All these steps are necessary to ensure the safe operation of the microcontroller.

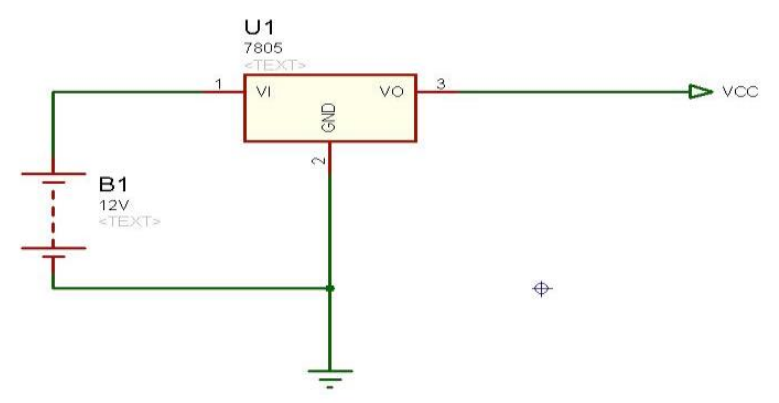

Figure 3: Power supply unit

\subsubsection{RFID Module:}

The RFID module comprised of an on-board ID-12LA series of ID Innovations Advanced RFID Reader design in the identification and tracking of RFID tags using its generated radio waves[12]. Figure 4 shows the components of the module. The generated radio wave by the RFID is constantly transmitted through its antenna at a frequency of $125 \mathrm{KHz}$ round the reader's field. By the process of electromagnetic induction passive tags at the reader's field are energized. Information stored in the tag is captured by the reader's antenna, filtered and processed on the embedded PIC16F887 microcontroller to extract the tags unique identity.

The RFID reader provides source of power for passive tags and is responsible for transmitting continuous signals at a frequency of $125 \mathrm{KHz}$, with the aid of its antenna receives and filters the signals, extracts the digital data from the processed signals and validates the tags using stored records. The corresponding circuit diagram of ID-12LA is shown in Figure 5.

4.2.3 The Microcontroller Unit: The microcontroller module was designed around PIC16F887 microcontroller which operates at $8 \mathrm{MHz}$ external clock frequency with Enhanced Universal Synchronous Asynchronous Receiver Transmitter (EUART) and Serial Peripheral Interface (SPI) modules. The controller was programmed in MiKroC to provide an enhanced data transmission and data control between the RFID reader and the library management software on the host PC. An indicator was incorporated to show when the system is ready for use. 
4.2.4 The Personal Computer Unit: This is the host system in which the developed automated library circulatory management software runs on. It serves as the display unit showing the operations that are being performed. The Personal computer is used as $S M S / E$ Mail Gate way responsible for sending automatic notification to patrons about borrowed materials and the date of expiration.

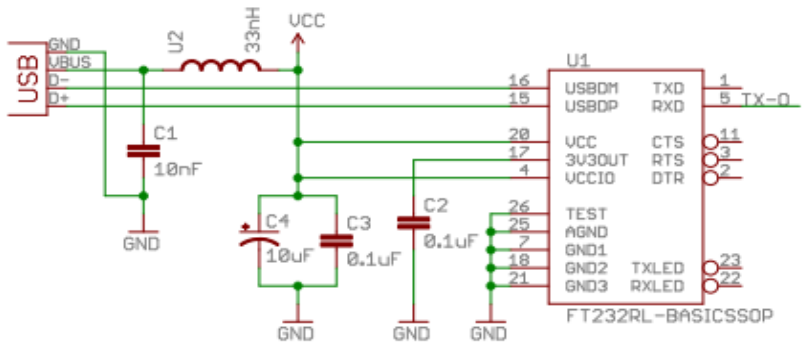

Figure 5: Circuit diagram of RFID reader [12]

\subsubsection{The Overall System Hardware Configuration}

The overall circuit diagram is shown in Figure 6. Pins ( 6 and 7, port C) of the PIC16F887 microcontroller is the TX and RX of the microcontroller, they were interfaced with the pins ( 1 and 5 ) of the RFID reader accordingly. The pins ( 0 and 1$)$ of port $B$ were connected to the red and green Light Emitting Diodes (LEDs) to serve as indicators.
Pins (5 and 6) of port A were connected to the external crystal oscillator for the microcontroller to operate at $8 \mathrm{MHz}$ frequency. At power $\mathrm{ON}$, the microcontroller sends a HIGH input through the RFID bus to enable initialization, this creates an enhance data transmission from RFID reader to the host PC.

\subsection{System Software Design Consideration}

The Library Management Software was developed using Java programming language, PHP, Hypertext Markup Language (HTML), Cascaded Style Sheet (CSS), JavaScript, MySQL as the database management system running on a Windows 8 Operating system platform and SMSlive247 Application Programming Interface (API). The developed software was designed to perform the following library tasks: Checking-in and Checking-out of Library patrons with secure RFID tags; Enrollment of library patrons; Authentication of authorized library patrons; Attendance of library patrons; Enrollment of Secure library books with secure RFID tags; Checking and Checking out of enrolled library books as well as notification services through GSM Short Message Services (SMS) to patrons on checked out books
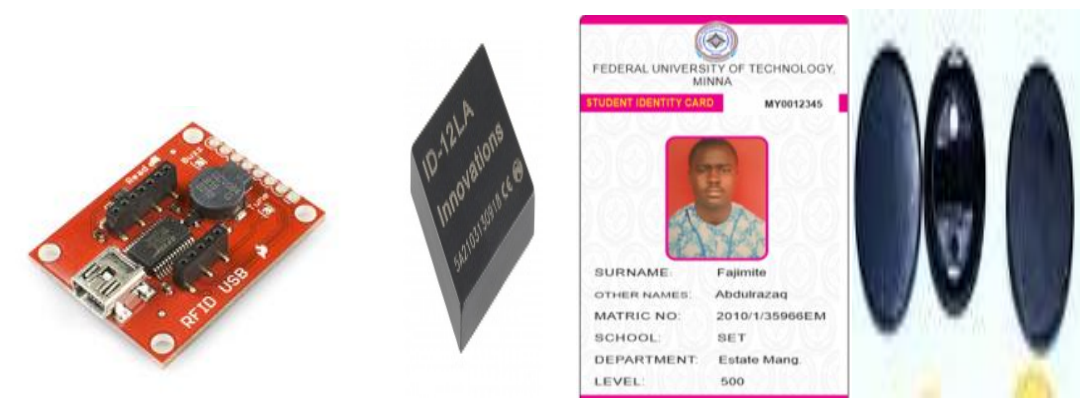

Figure 4: RFID reader module and tags (adapted from [12])

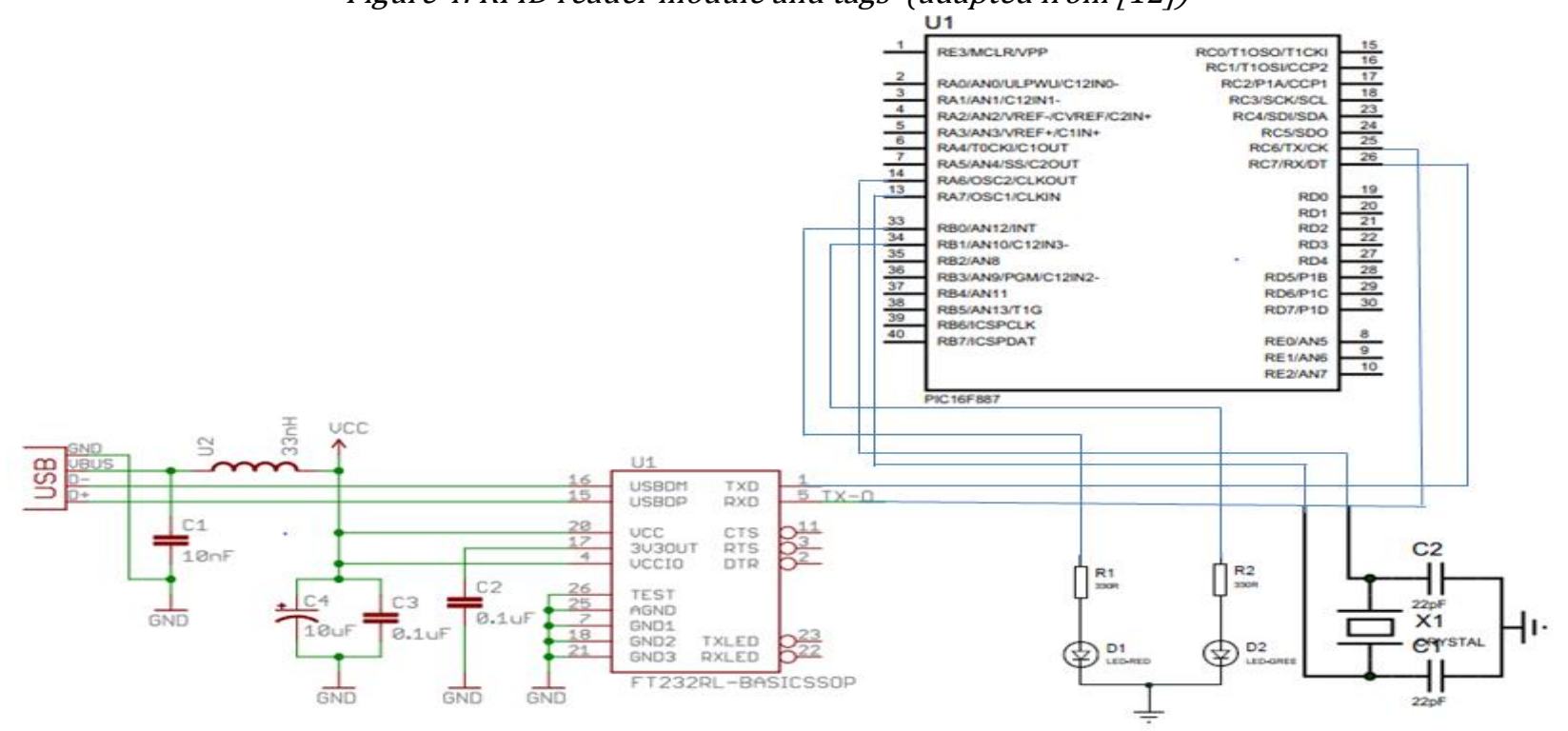

Figure 6: Overall circuit diagram of RFID reader of the secure library circulatory system 


\subsubsection{Overall System Architecture:}

The architecture shown in Figure 7is the overall system architecture of the Secure Library Circulatory System of the mini-library in the School of Information and Communication Technology (SICT), Federal University of Minna, Niger State, Nigeria adopted as the test bed. The architecture can be adapted to accommodate other library operations beyond circulation with slight modifications. From Figure 7, the system security at the database level starts from the enrolment of patrons, during which the Library Management Software encrypts the patron's information using 192-bit Advance Encryption Standard (AES), the decryption occurs when the tag is swiped at the reader. For registered users, the system decrypts and grants them access while for unregistered users, the system shows invalid user.

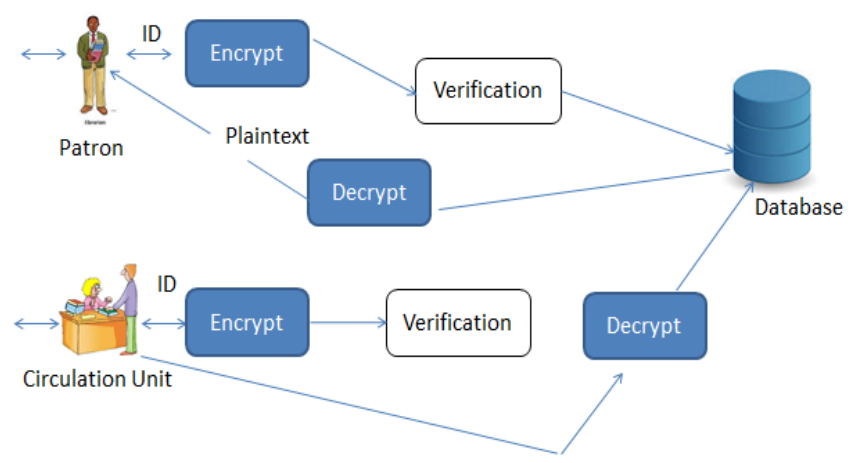

Figure 7: System architecture of the secure library circulatory system

4.3.2 System Modeling: The Secure Library Circulatory System was modelled with the entity-relationship diagram, use-case diagram, activity diagram diagrams and the sequence diagram using object oriented design paradigm. The entity-relationship diagram, use-case diagram and sequence diagram of the system are shown in Figures 8a, 8b and 9a, 9b respectively.

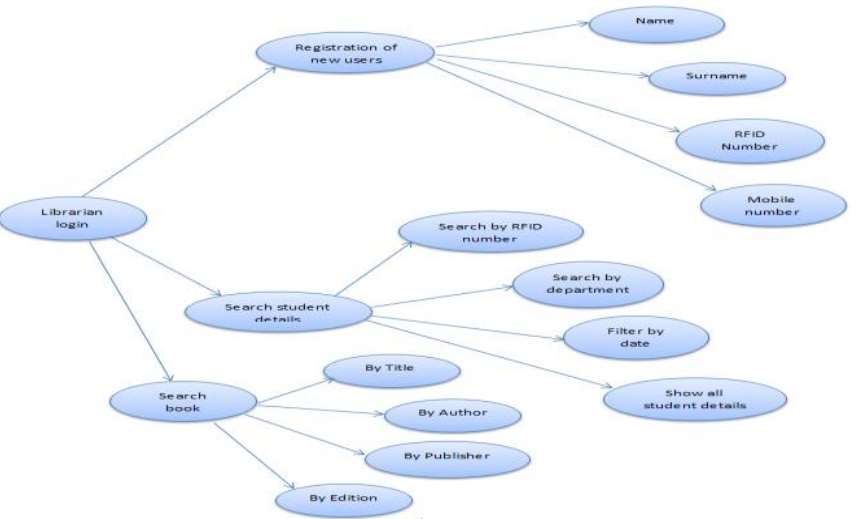

Figure 8a: Librarian entity relationshipship diagram of the secure library circulatory system

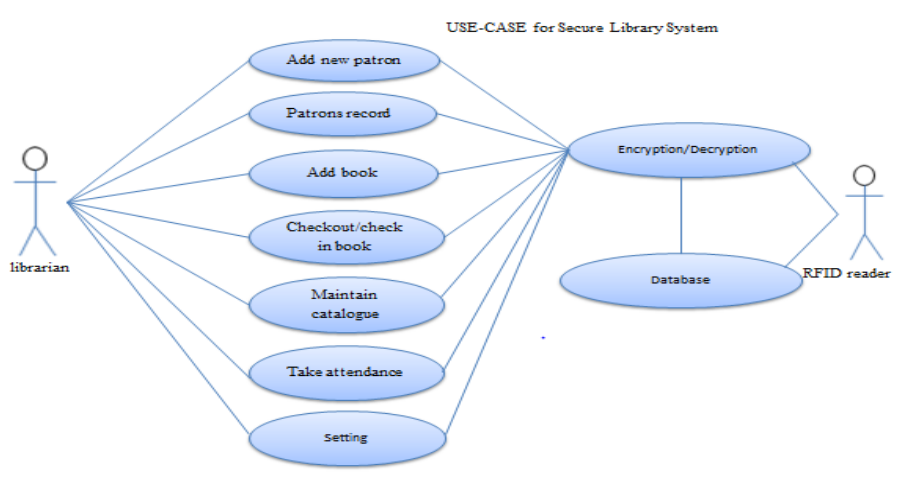

Figure 8b: Librarian use case diagram of the secure library circulatory system

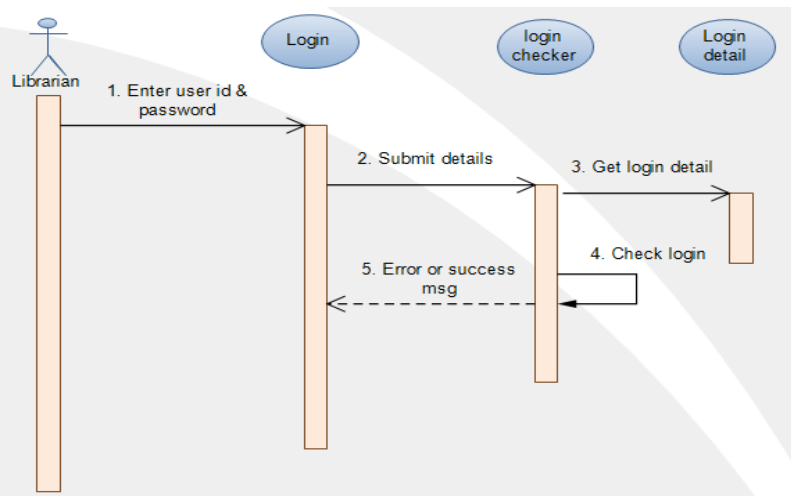

Figure 9a: Sequence diagram of the secure library circulatory system

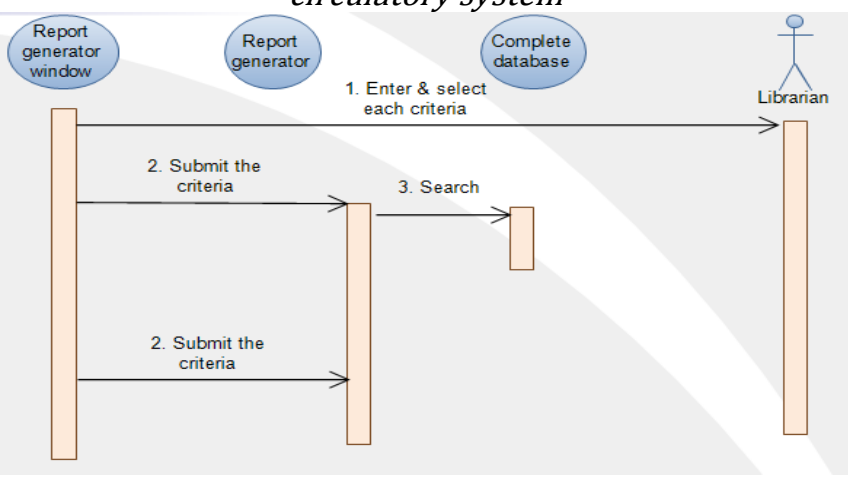

Figure 9b: Sequence diagram of the secure library circulatory system

4.3.3 System Security Design Consideration: The principle of symmetric cryptography using Advanced Encryption standard (AES) was applied to secure the patron's data in the database. AES is a symmetric block cipher. By definition, symmetric algorithms have one key for both the sender and the receiver need to have the same key. A block cipher is a method of encrypting text in which a cryptographic key and algorithm are applied to a block of data at once as a group rather than to one bit at a time. Advance Encryption Standard of 192-bit key length was used 
because the longer the key used for encryption, the stronger the security strength [10] [13].

\section{RESULTS AND DISCUSSIONS}

Figures $10,11,12,13,14$, and 15 shows the impact of the developed system on security of the Library Circulatory Unit for both library patrons and administrators using appropriate software and hardware techniques discussed in the previous sections of this paper. Figure 10 shows the administrator login page. To use the Library Management Software, the administrator needs to enter a valid user name and password to operate library circulation operations.
Figure 11 shows an interface for new patron's registration by the library administrator into the library. The library administrator does registration by first swiping an RFID tag over the reader and filling out the provided form with the patron personal information. Figure 12 shows an interface of kept records after successful enrollment of patrons, displaying vital information of the patrons.

Figure 13 shows an interface for enrolled books newly acquired by the library administrator. This requires the library administrator tagging every book with an RFID tag and swiping it over the RFID reader.

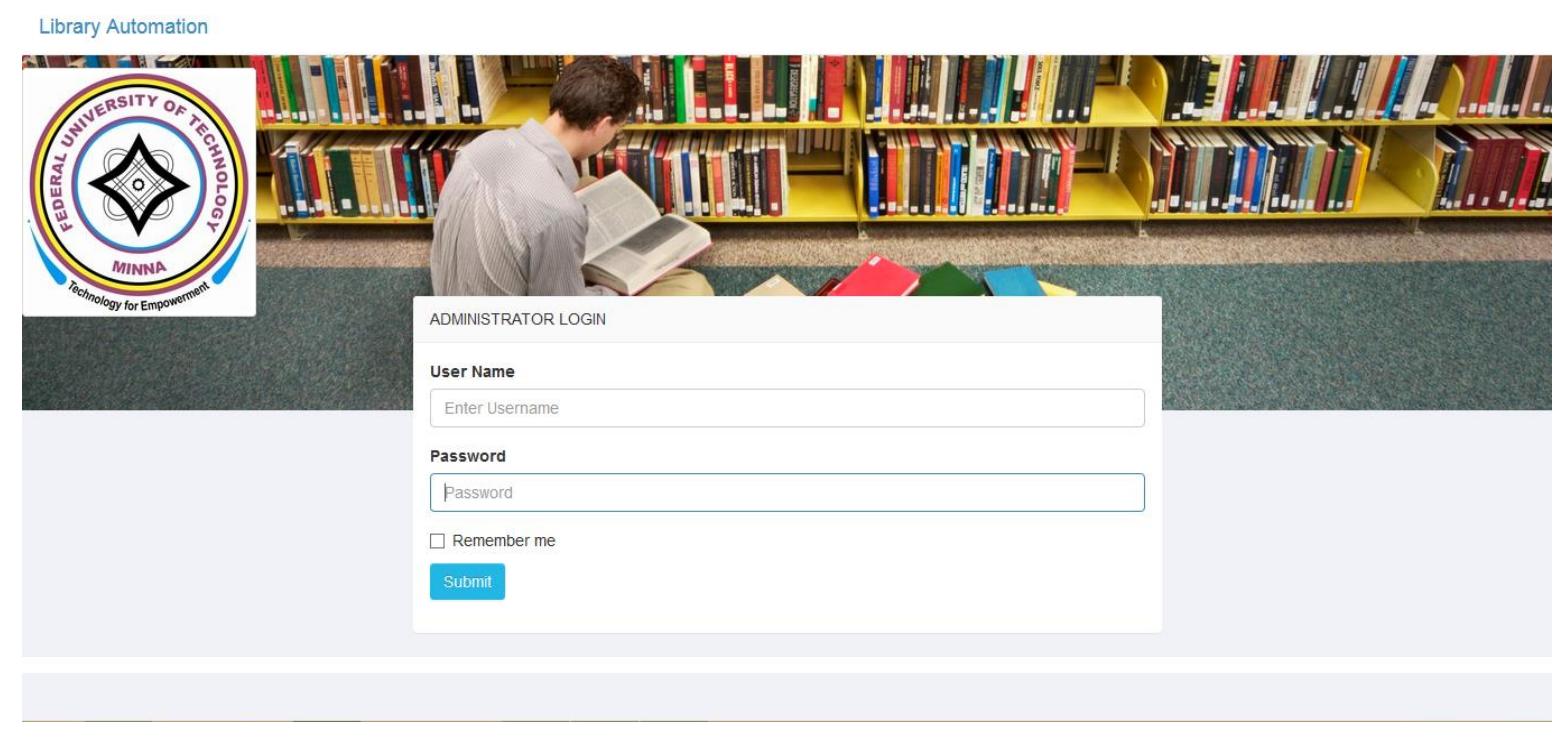

Figure 10: Administrator login interface

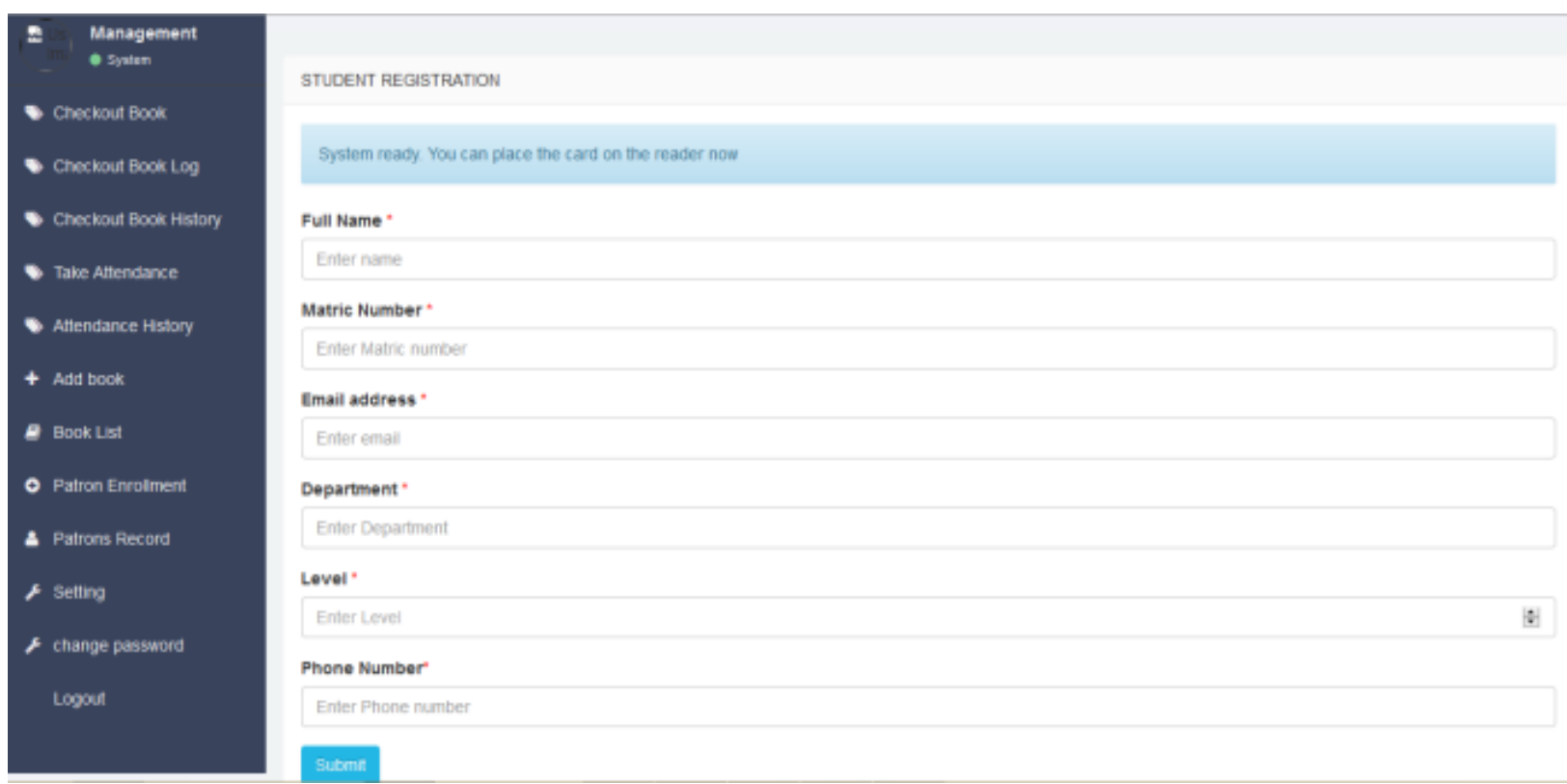

Figure11: Patron's enrolment interface 

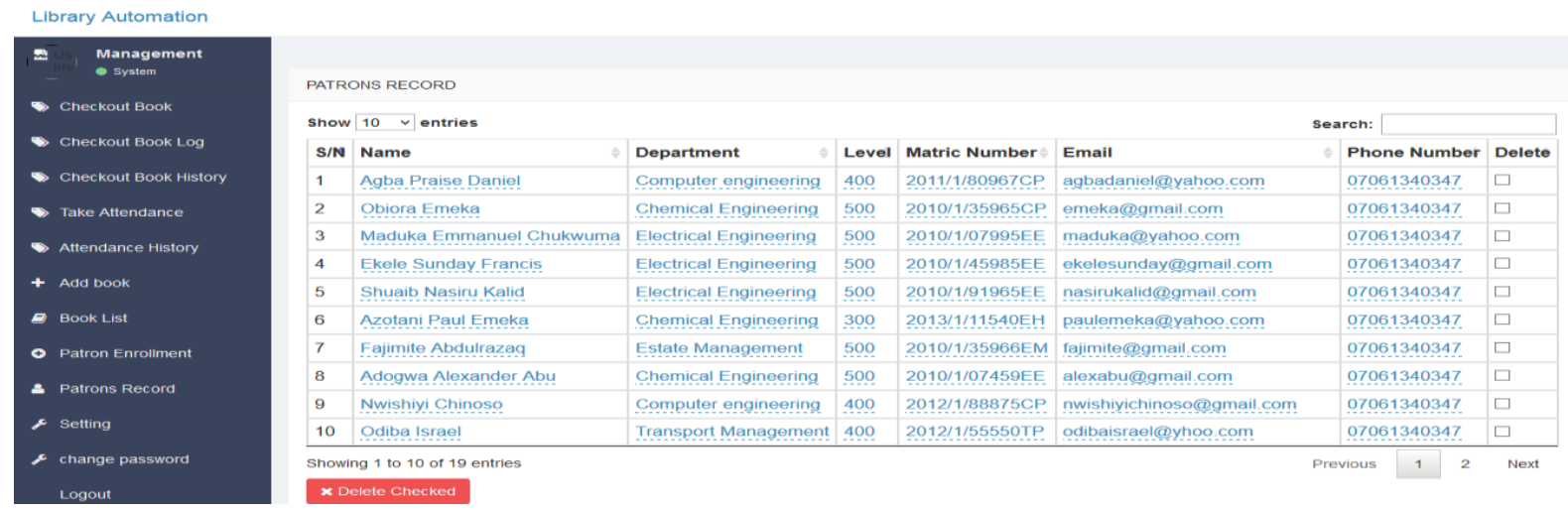

Figure 12: Patrons record page
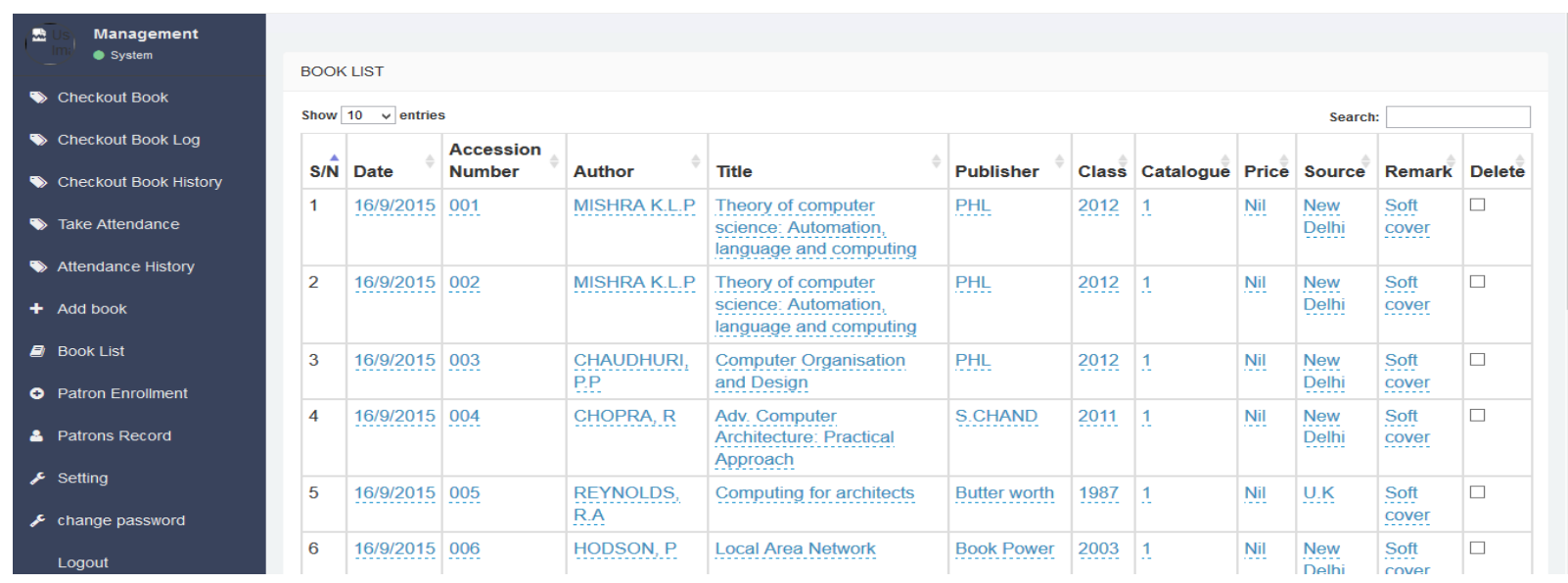

Figure 13: Enrolled and secured book interface

Figures 14a and Fig.14b show interfaces for chargingin and charging-out library patrons to access into the library facility. These operations were performed and monitored as patron's swipe their cards (RFID tags) across the RFID reader at the point of entry and exit from the library. The patron's details, time in and time signed out of each patron is registered automatically. Figure 15 shows an interface for checking out books borrowed to patrons by swiping the patron's card and the book simultaneously for validation purpose. Figure 16 shows the history of checked out books.

\subsection{Operation of the System}

The developed system (shown in Figure 17) transmits information from RFID module to Programmed Host PC to automate the checking-in and checking-out of patrons alongside sending of notifications to patrons. For the process of patrons charging-in and chargingout shown in Figure 13, patrons are required to swipe their library cards over the reader.

The RFID reader collects the encoded information and sends it to the host system. The acquired data is decrypted and compared to information stored in the database. If the comparison is for a valid user, the patron's information is displayed on the PC alongside the time/date of signing in. Otherwise, an invalid card message prompts on the display of the host PC.

Similar process of swiping library card over the RFID reader is repeated on exit from the library, patrons are automatically signed out alongside their details and time signed out. For book checking-in/checking-out process, tagged books and the patron's library card are swiped simultaneously for validation (Figure 14). The systems automatically enroll the patron alongside the borrowed book on the check-out book log stating date checked-out and date of return of book. On the date of return of book, If the book has not been returned, the system sends out notification message through SMS to the patron reminding him/her about the borrowed book. On returning the book, it is checked-in by clicking on return book. For system security, symmetric cryptographic measures were implored. 

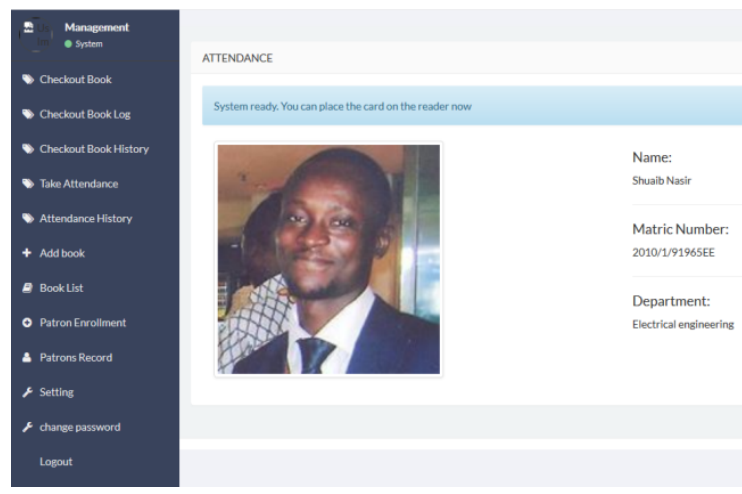

Level:
500

Email:

isreellovedifieegmail

Phone number:
is signining intor We

Figure 14a: Patrons real time library attendance tracking
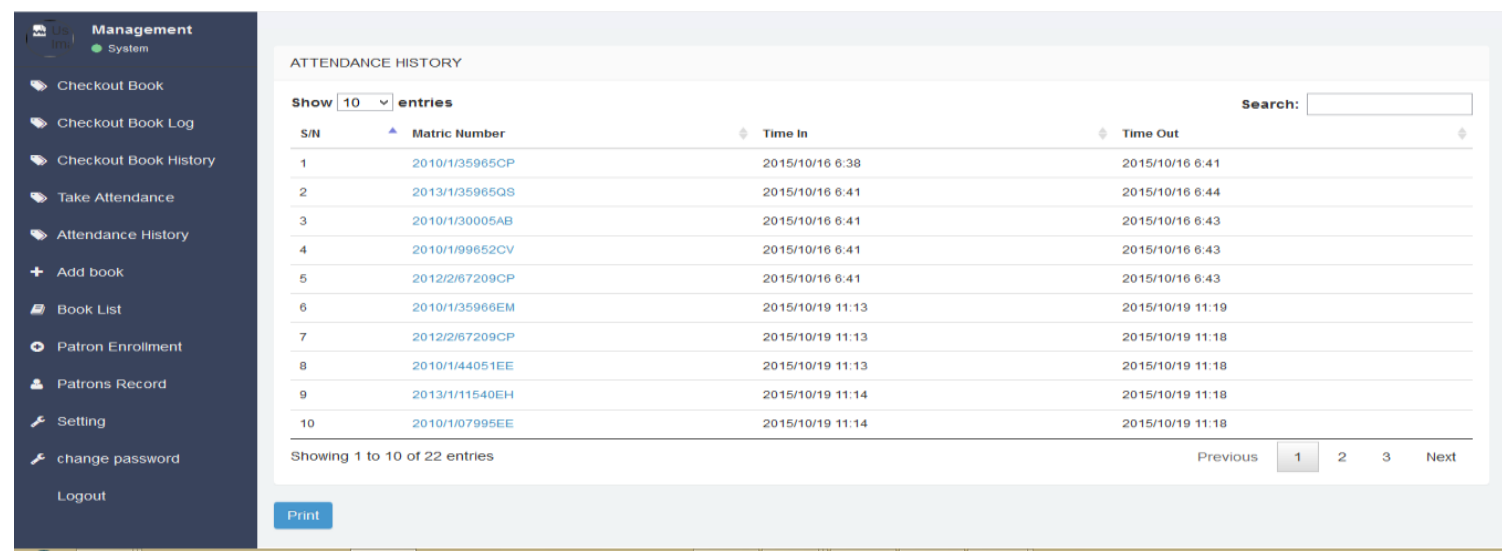

Figure 14b: Patrons library attendance history
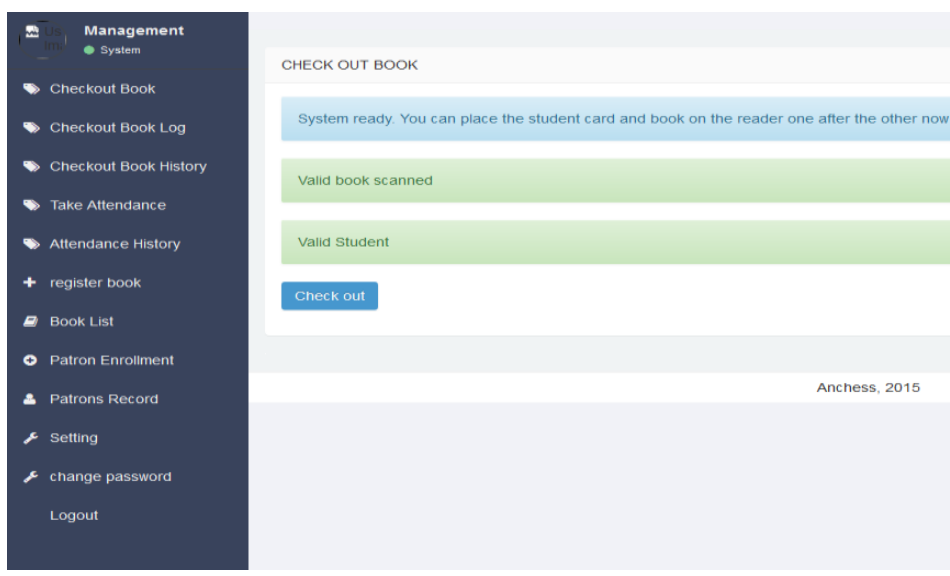

System ready . You can place the student card and book on the reader one atter the other now

Valld book scanned

valld student
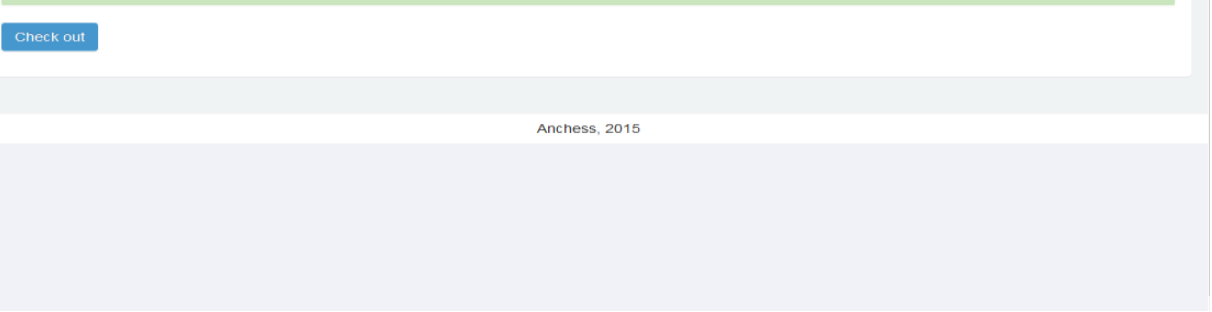

Figure 15: Process of checking out library book interface

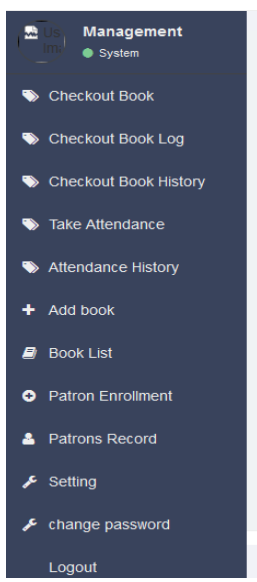

CHECKED OUT BOOK HISTORY

Show $10 \vee$ entries

Search:

S/N Matric Number Book Title

1 2010/1/30005AB Adv. Computer Architecture: Practical Approach

Checked out Date Return Date Duration

2 2012/1/55550TP Computing for architects

2015/9/16 2015/9/26 - - 2 days

3 2012/2/67209CP Adv. Computer Architecture: Practical Approach

$2015 / 9 / 16 \quad 2015 / 9 / 26 \quad-1$ days $2015 / 9 / 19 \quad 2015 / 9 / 29 \quad-1$ days

4 2012/1/55550TP Introduction to Computing systems from Bits and Gates to $\mathrm{C}$ and beyound

5 2010/1/35966EM Theory of computer science: Automation, language and computing

$2015 / 9 / 21$

$2015 / 9 / 21-1$ days

$62010 / 1 / 35965 \mathrm{CP}$ Theory of computer science: Automation, language and computing

$2015 / 9 / 23$

$2015 / 9 / 23-1$ days

Showing 1 to 6 of 6 entries

\begin{tabular}{l|l|l} 
Previous & 1 & Next
\end{tabular}

Print

Figure 16: Checked out books history 


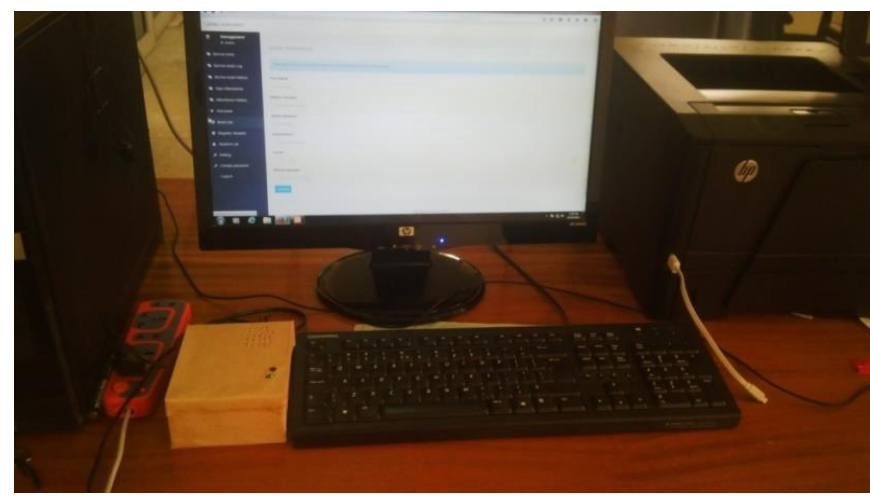

Figure 17: Developed prototype for library circulatory operation

A 192-bit Advance Encryption Standard (AES) was adopted. As a cipher, AES has proven to be reliable, the only successful attack against it have been side channel attacks which is a weaknesses found in the implementation or key management of certain AES based encryption [13]. Figures 18 and 19 show the system flowchart for Charging-in/Charging-out Library patron and book borrowing respectively

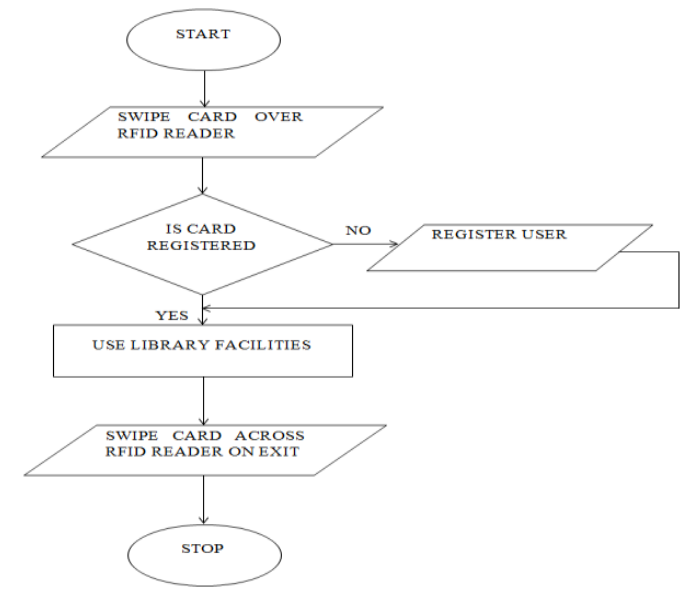

Figure 18: Flow chart of the patron's chargingin/charging-out

\subsection{System Performance Evaluation}

The developed system was evaluated on the accounts of the response of the RFID reader and tag during the circulation procedure in the library. These are the percentage read range and tag placement. Percentage read rate refers to the total number of RFID labels (mapped to a unique library patron) that are read by the RFID reader at $3.2 \mathrm{~cm}$ read range of the passive tags into cognizance, while tag placement is concerned with placing of tag in a position to provide high optimization in readability. From the result obtained in Figures 20 and 21, the percentage read range of RFID tags decreases with an increase in the distance of RFID tag from reader. The result also showed that, surface area of tags also affects the readability of RFID tag. These results are consistent for low passive application of $125 \mathrm{kHz}$ passive tags for optimum identification of registered patrons and resources for secure and digitized library circulation operations.

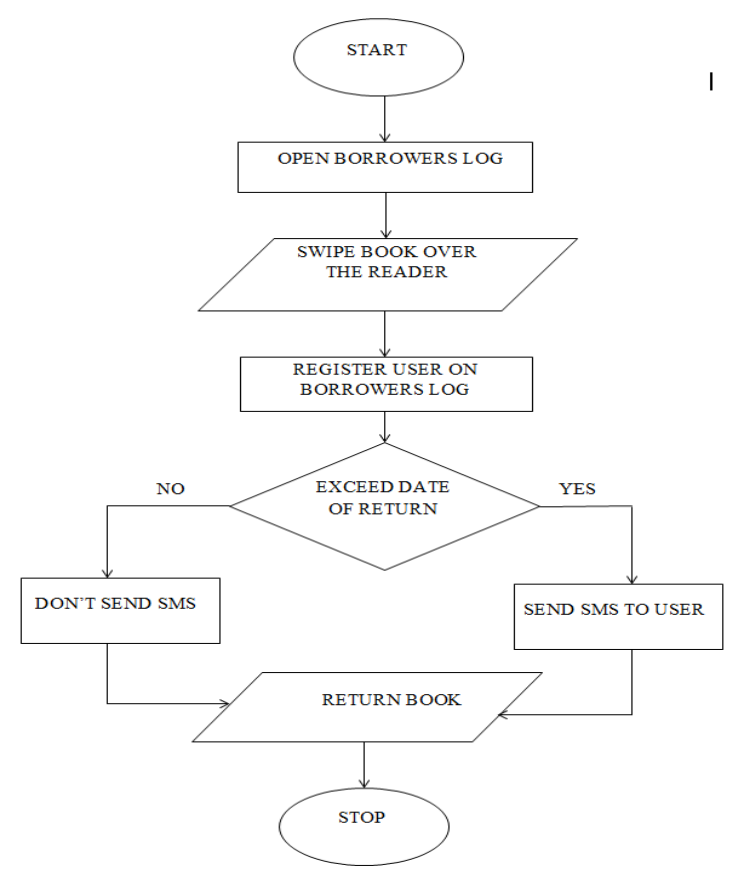

Figure 19: Flow chart of book borrowing system

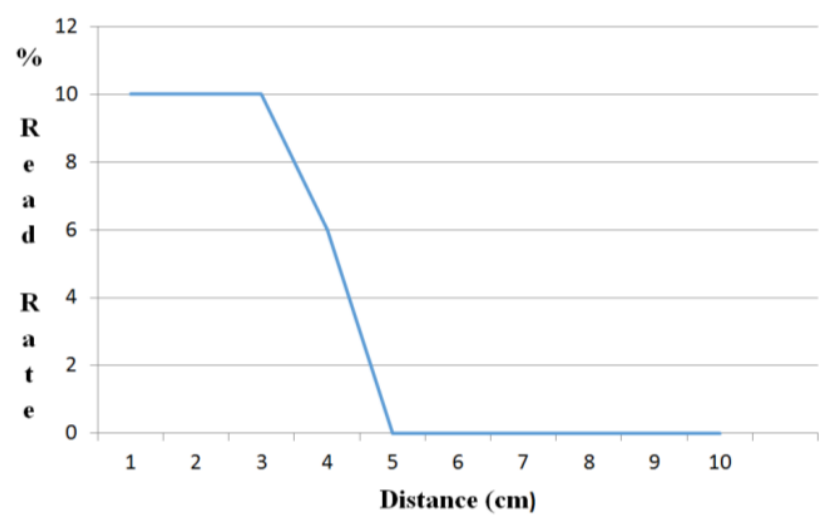

Figure 20: Response of Patrons identification card (tags) from RFID reder

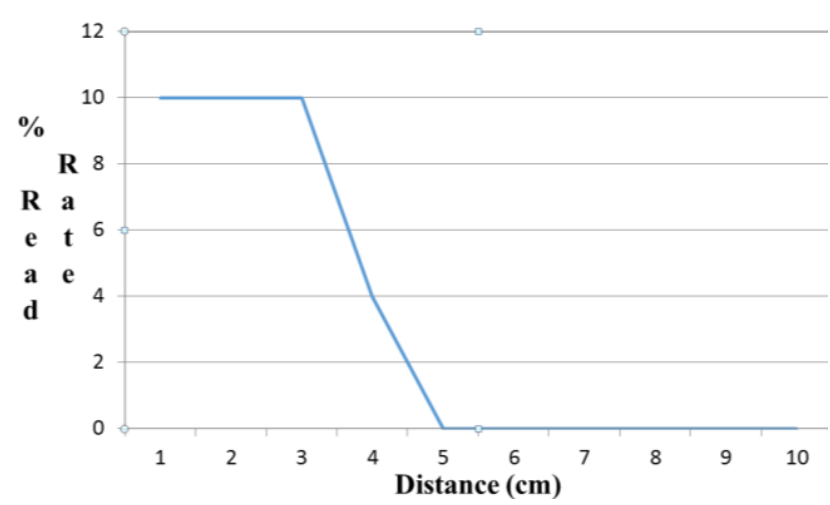

Figure 21: Response of secure/tagged book from RFID reader 


\section{CONCLUSION AND FUTURE WORK}

In this work, digitized and secure library circulatory operation using RFID technology with notification service has been successfully presented. The operational model of the SICT mini library of FUTMINNA Gidan Kwano, Niger State, Nigeria was used as the Test-bed. Time management is of paramount importance to any organization and as such the developed system, if adopted and used will reduce time wastage, improper identification of library resources and errors made in the cause of execution of library circulatory routine operations. The system would also help librarians to have proper record management of library resources, registered patrons and reading transactions of patrons with available hard and soft resources.

The developed system in its functionality performs effectively. Nevertheless, we intend to improve the system with the inclusion of high tech RFID reader having an operating frequency of about $13.56 \mathrm{MHz}$ alongside an active transponder to enable communication from a far distance. The extension of security from RFID reader and the transponders so as to further ensure confidentiality of patron's information and prevent tags cloning and the development of a single system with multi tag access permission. Future research direction could also address identification of returned mutilated books. Mutilation is the deliberate tearing of significant parts of a library book by a malicious library patron.

\section{ACKNOWLEDGEMENTS}

The authors are grateful to the Library staffs at FUTMINNA Gidan Kwano main library and the SICT mini library for their support, advice and unlimited contribution of their expertise in the process of conceptualization, testing and evaluation of this work.

\section{REFERENCES}

[1] K. T Anuradha and R. Sivakaminathan, "Enhancing Full Text search eal capability in Library Automation package": A case study with Koha and Greenstone Digital Library Software - PWC.CSIT, Vol. 1, pp330 335. [Online]. Available: www.IPCSIE.com/vol1/60S105.pdf

[2] A. Narayanan, S. Sanjay and M. Somasekharan, "Implementing RFID in Library: Methodologies, advantages and disadvantages". Scientific Information Resources Division, IGCAR, Kalpakkam. Pp 271-279.
[3] N. Michael, "The impact of information and communication Technology (ICT) complaint Librarians on Library Services Delivery in Academic Library: A case of National Open University of Nigeria (NOUN) Library". The International Journal of Engineering and Science, Vol.2, Issue 8. pp 6, 2013.

[4] P. Prabhat and K. D. Mahajan, "Application of RFID Technology in Libraries and Role of Librarian". College of Diary Technology, Pusad, Yavatmal. Pp 212. [Online]. Available:www.eprint.rclix.org/ 15253/3/RFID.pdf.

[5] O. M. Olaniyi, A. Omotosho, E. A. Oluwatosin, O.K. Towolawi and G.C. Grant-Ezeronye, "Application of information Technology to the management of Library's Desk". DESIDOC Journal of Library \& Information Technology, Vol. 32, No. 6, Pp. 516-517. 2012.

[6] S. L. Faisal and B. Surendran, "Automation of Library at Kendriya Vidyalaya Pattom Thiruvananthapuram". 2008. [Online]. Available: https://librarykvpattom.files.wordpress.com/2008/ 07/library-automation.pdf

[7] S. Kinoshita, M. Ohkubo, F. Hoshino, G. Morohashi, O. Shionoiri and A. Kanai, "Privacy enhanced active RFID tag". Cognitive Science Research PaperUniversity of Sussex CSRP, 577, Pp. 100. 2005.

[8] L. A. Akinyemi, O. O. Shoewu, N .T. Makanjuola, A. A Ajasa, C.O Folorunso and F.O Edeko, "Design and Development of an RFID Based Library Books Security System", African Journal of computing and ICT. Vol. 7, No. 2, Pp. 85-92. 2014.

[9] E. O. Edward and P. E Orukpe, "Development of RFID Based Library Management system and User Access Control", Nigerian Journal of Technology, Vol. 33 No. 4. Pp 574-584. 2014.

[10] O. M. Olaniyi, T. A. Folorunso, A. Omotosho and I. I Alegbeleye. "Securing Digitalized Campus Clinic Healthcare Delivery System". In Proceeding of AIT'15. Federal University of Agriculture, Abeokuta, Ogun, State Nigeria. Pp 18-26. 2015.

[11] 0. M. Olaniyi, D. O. Adewumi, O. Shoewu, O. W. Sanda. "Lecture Attendance System Using Radio Frequency Identification and Facial Recognition". Computing, Information Systems and Development Informatics Journal 3(2), Pp 35-38. 2012.

[12] 2015 Sparkun. RFID Starter kit. [Online]. Available: https://www.sparkfun.com/products/13198.

[13] M. Prerna and S. Abhishek. "A Study of Encryption Algorithms AES, DES and RSA for security". Global Journal of Computer Science and Technology Network, Web and Security. Vol. 13, Pp 15-17. 2013. 